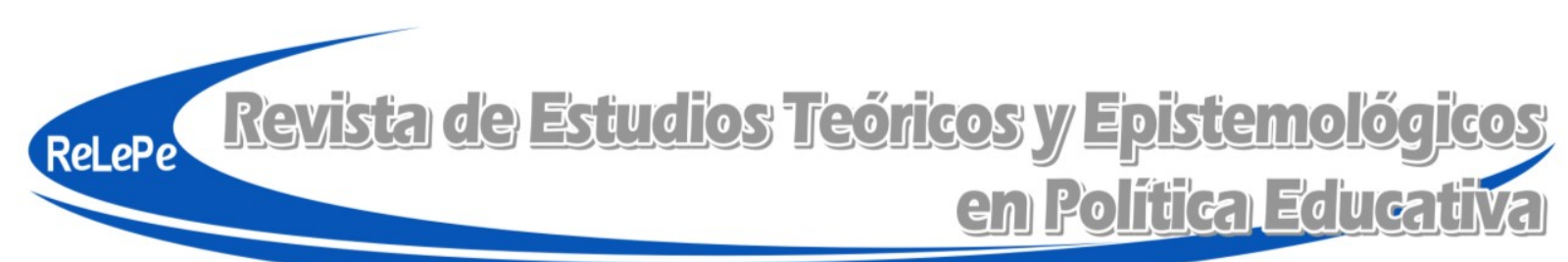

ISSN 2409-3696

DOI: $10.5212 /$ retepe.v.4.008

\title{
A implementação do Programa de Alfabetização na Idade Certa no Estado do Ceará
}

\author{
Maria Océlia Mota \\ Pontifícia Universidade Católica do Rio de Janeiro (PUC-Rio) \\ oceliamota@gmail.com \\ Liana de Andrade Biar \\ Pontifícia Universidade Católica do Rio de Janeiro (PUC-Rio) \\ lianabiar@gmail.com \\ Maria Elizabete Ramos \\ Pontifícia Universidade Católica do Rio de Janeiro (PUC-Rio) \\ mbete.ramos@gmail.com
}

Resumo: Por meio de seus resultados exitosos, o Programa de Alfabetização na Idade Certa (PAIC) colocou o Ceará em evidência no cenário educacional brasileiro e ganhou destaque como expressão máxima do regime de colaboração no estado. O objetivo do PAIC é que todas as crianças sejam alfabetizadas até os oito anos de idade, e tem na formação continuada o componente essencial da profissionalização docente. Em função da complexidade de atribuições e competências nas formas de coordenação, que envolve repasse de recursos e mecanismos de indução para adesão a essas políticas, esse trabalho pretende investigar como acontece o alinhamento discursivo na implementação da política. A metodologia da pesquisa se utiliza da análise da narrativa para interpretar a percepção dos agentes que interagem na implementação do PAIC. Os resultados mostram que os diferentes níveis hierárquicos da burocracia educacional se refletem nas narrativas e permitem estabelecer um contraste entre as formas de interação dos agentes e suas respectivas percepções e margem de atuação.

Palavras-chave: PAIC. Colaboração. Implementação. Análise de narrativa. Alfabetização.

\section{The implementation of Literay at the Right Age Program in the Ceará State}

\begin{abstract}
Through its successful results, the Literacy Program in the adequate age (PAIC) placed Ceará in evidence in the Brazilian educational scenario, gaining prominence as the maximum expression of the collaborative system in the state. The aim of the PAIC is that all children are literate until the age of eight, and have in teacher training the essential component of teacher professionalization. Due to the complexity of attributions and competences in terms of coordination, which involves the transfer of financial resources and mechanisms of induction for adherence to these politics, this work aims to investigate how the discursive alignment occurs in its implementation. The research methodology uses narrative analysis to interpret the perception of the agents that interact in the implementation of the PAIC. The results show that the different hierarchical levels of the educational bureaucracy are reflected in the narratives and allow to establish a contrast between the agents' interaction forms and their respective perceptions and scope of action.
\end{abstract}

Keywords: PAIC. Collaboration. Implementation. Narrative analysis. Literacy. 


\section{La implementación del Programa de Alfabetización en edad adecuada en el Estado de Ceará}

Resumen: Por medio de sus resultados exitosos, el Programa de Alfabetización en la Edad Adecuada (PAIC) colocó a Ceará en evidencia en el escenario educativo brasileño y se destacó como expresión máxima del régimen de colaboración en el estado. El objetivo del PAIC es que todos los niños sean alfabetizados a los ocho años de edad, y tienen en el formación continua el componente esencial de la profesionalización docente. En función de la complejidad de atribuciones y competencias en las formas de coordinación, que involucra la transferencia de recursos y mecanismos de inducción para la adhesión a esas políticas, este trabajo pretende investigar cómo ocurre la alineación discursiva en la implementación de la política. La metodología de la investigación se utiliza del análisis de la narrativa para interpretar la percepción de los agentes que interactúan en la implementación del PAIC. Los resultados muestran que los diferentes niveles jerárquicos de la burocracia educativa se reflejan en las narrativas y permiten establecer un contraste entre las formas de interacción de los agentes y sus respectivas percepciones y margen de actuación.

Palabras claves: PAIC. Colaboración. Implementación. Análisis de narrativa. Alfabetización.

\section{Introdução}

O Programa de Alfabetização na Idade Certa (PAIC), que visa a assegurar que todas as crianças estejam alfabetizadas até os oito anos de idade, tem sido reconhecido como uma política exitosa devido ao alinhamento entre diferentes entes federativos e ao regime de colaboração estabelecido entre eles, além da interação entre os diferentes atores envolvidos. O objetivo principal deste trabalho ${ }^{1}$ é investigar como acontece o alinhamento discursivo da política com as práticas pedagógicas na percepção dos agentes que participam do programa, professores, coordenadores e gestores escolares e municipais. Buscamos compreender como esses atores produzem sentido e dão significado às suas ações, pois o que eles pensam e no que acreditam têm implicações para o processo de implementação das políticas.

Muller e Surel (2002, p.29) destacam que as políticas, no sentido da ação pública (policies), vinculam-se às dinâmicas e aos atores que caracterizam a atividade política (politics) e aos processos e às interações que concorrem para a formação e a evolução de tudo o que remete a esfera da política (polity). Por compreender o processo de implementação como forma de argumentação e de produção de sentido (CAPELLA, 2016), não consideramos a implementação como mera execução de um plano que foi formulado por outros agentes. Para muitos autores, o processo de implementação da política é percebido como um processo interativo de formulação, implementação e reformulação (MAZMANIAN; SABATIER, 1983 apud LIMA; D'ASCENZI, 2013, p. 104). Nesse caso, a política permite modificações no processo de implementação e, portanto, não haveria "uma" única interpretação ou uma única maneira de se implementar a política. Se a implementação não corresponde à simples execução da política, o foco recai sobre a capacidade de agência dos diversos atores envolvidos na produção de políticas, que podem representar diferentes níveis da burocracia. Pensar em estratégias de melhoria dos serviços públicos requer o entendimento acerca dos processos pelos quais as políticas são realizadas.

Lima e D'Ascenzi (2013) sinalizam que a literatura sobre os modelos analíticos de implementação de politicas públicas identifica "duas abordagens hegemônicas". O primeiro modelo considera a implementação como um plano em que os órgãos públicos desenvolvem a formulação da política a ser executada. Esse modelo é entendido a partir de uma visão de cima

\footnotetext{
${ }^{1}$ O presente trabalho foi realizado com apoio da Coordenação de Aperfeiçoamento de Pessoal de Nível Superior Brasil (CAPES) - Código de Financiamento 001 e do Conselho Nacional de Desenvolvimento Científico e Tecnológico (CNPq).
} 
para baixo, ou de um modelo top-down, que tem como foco analítico o controle e a hierarquia. $\mathrm{O}$ segundo modelo entende a implementação a partir de uma visão de baixo para cima, também chamado de modelo bottom-up, supõe que a política permite modificações no processo de tradução da intenção em ação. $O$ processo de implementação pode ser também compreendido como forma de argumentação e de produção de sentido, tanto na sua formulação como na sua implementação. Isso significa olhar não apenas para os aspectos formais e hierárquicos da política, mas também para a forma pela qual os agentes atuam.

Nesta intenção, realizamos neste trabalho uma pesquisa bibliográfica, a partir das leis e dos documentos sobre o PAIC e uma análise qualitativa de entrevistas semiestruturadas com gerentes do PAIC de três municípios da região do Cariri, administrados pela Coordenadoria Regional de Educação (Crede 18), e com diretores, professores e coordenadores de oito escolas localizadas nesses municípios. Nesse estudo, daremos destaque aos agentes "de nível de rua" (LIPSKY, 2010), que estão em contato direto com os beneficiários da política, e aos agentes de "médio escalão" (CAVALCANTE; LOTTA, 2015), que agem como intermediadores entre o topo e a base da estrutura organizacional da política, fazendo com que as decisões sejam colocadas em ação.

A análise procurará responder mais especificamente as seguintes questões: como os agentes implementadores percebem as ações desenvolvidas pelo eixo de avaliação do PAIC segundo suas narrativas?; Quais seriam as suas percepções acerca do sistema de premiação?; Há diferenças entre as narrativas dos "burocratas de médio escalão" e dos "burocratas de nível de rua"?; Como avaliam o programa?

Importa ressaltar que o processo de implementação da política envolve questões relativas à distribuição de poder e de atribuições entre os entes federados e os atores envolvidos, bem como às questões relacionadas aos arranjos institucionais, incluindo coordenação dos agentes implementadores, e o espaço de discricionariedade destes agentes. A forma como os implementadores vivenciam as dimensões organizacionais e as relações interpessoais no processo de implementação produz a (re)construção coletiva do plano apresentado, daquilo que fora concebido na sua formulação. Dessa maneira, ganha relevância a dimensão interpretativa, uma vez que a forma como os agentes diretamente envolvidos na implementação da política produzem sentido sobre a política formulada faz com que o que antes fora pensado ganhe novos contornos. Embora o mais comum seja pensar o desenho das políticas, monitoramento, avaliação, sem considerar os agentes burocratas, as pesquisas mais recentes no campo das ciências políticas vêm mostrando como é importante compreender a maneira como a burocracia atua, e conhecer os elementos que influenciam sua motivação.

Cabe mencionar que o presente trabalho é um desdobramento da pesquisa de doutorado de uma das autoras, e os dados utilizados aqui foram gerados na elaboração da tese, cuja metodologia, à época, envolveu análise documental, observação e entrevistas. A análise documental se realizou a partir da legislação da política, para responder a questões no tocante à formulação do PAIC.

O texto encontra-se organizado em cinco seções, sendo a primeira esta introdução. $\mathrm{Na}$ segunda seção, abordaremos os modelos analíticos de implementação. $\mathrm{Na}$ terceira seção, apresentaremos o contexto de mobilização social a partir do qual nasceu o Programa de Alfabetização na Idade Certa (PAIC). A quarta seção traz algumas informações sobre campo que informará a análise de narrativas e encaminhará as questões de pesquisa à luz dessa análise. Por fim, a quinta seção traz as considerações finais. 


\section{Modelos analíticos de implementação}

Embora haja diferentes concepções sobre os processos de implementação, todas elas destacam como elemento central a atuação dos atores responsáveis pelas tomadas de decisões nos processos de implementação. A questão central colocada pelas investigações é: quais são os atores que têm influência no processo de implementação e quais os impactos que cada um deles produz sobre os resultados das políticas? É com o objetivo principal de responder a essa questão que os estudos focalizam o papel das burocracias nos processos de implementação.

Apesar de escassos, alguns estudos sobre implementação já foram realizados. Os primeiros desses estudos compreendiam a implementação "como um processo hierárquico" (LOTTA, 2015, p. 34), que vinha de cima para baixo e que seguia a seguinte lógica: as políticas públicas eram formuladas por agentes superiores da estrutura hierárquica e passariam ao sistema administrativo de execução, sendo transformadas em práticas operacionais a serem implantadas. Assim, o modelo top-down enfatiza a separação entre a política e a administração, tendo como foco analítico o controle e a hierarquia. Trata-se de estipular um ideal normativo de colocar a política em ação, rigorosamente como foram concebidos. O modelo bottom-up, por sua vez, parte do pressuposto de que a política permite modificações, sendo a fase de implementação permeada de transformações e adaptações. Se, nos estudos com abordagem top-down, a atenção volta-se para as metas e os planos da política, na visão bottom-up, o enfoque são os processos. Se as políticas são realizadas com base na interação de diversos atores que transformam os processos se faz necessário inserir na pauta analítica a atuação dos burocratas.

No bojo desses estudos sobre burocracias, o estudo pioneiro de Lipsky (2010), denominado street-level bureaucracy, cunhou o termo "burocratas de nível de rua" para se referir aos "funcionários que trabalham diretamente no contato com os usuários dos serviços públicos, como, por exemplo, policiais, professores, profissionais da saúde, entre outros" (LOTTA, 2015, p. 43). São os agentes responsáveis pela entrega final da política, e a sua interpretação e atuação é fundamental para os resultados da política. Segundo Lipsky, "as decisões dos burocratas de nível de rua, as rotinas que eles estabelecem e os artifícios que eles inventam para lidar com as incertezas e as pressões do trabalho acabam se transformando nos serviços públicos que eles são responsáveis por executar" (LIPSKY, 1980, apud PIRES, 2017, p. 5).

Olhar para a atuação desses burocratas implica em olhar, também, para as formas como eles constroem suas ações. Por um lado, essas ações são conformadas pelas normas e regras institucionais e, por outro, são fundamentadas em crenças e valores individuais. Este segundo aspecto é denominado pela literatura como exercício da discricionariedade, definido como o momento em que os burocratas determinam a natureza, a quantidade e a qualidade dos benefícios/sanções. Embora haja regras e normas que moldem alguns padrões de decisão, ainda assim, esses burocratas gozam de certa "autonomia para decidir como aplicá-las e inseri-las nas práticas da implementação" (LOTTA, 2015, p. 46). De acordo com Oliveira (2012), os "burocratas de nível de rua" são os funcionários que trabalham nos guichês; nos consultórios; nas salas de aula; nos pátios dos presídios; nas esquinas das ruas, enfim, são os responsáveis por entregar o serviço ao beneficiário da política. Os estudos sobre os agentes implementadores que estão na linha de frente do relacionamento com os usuários dos serviços públicos, e cuja atuação vem sendo percebida como essencial para a eficiência da política, têm se ampliado nos últimos tempos. Pode-se observar, portanto, que as investigações sobre implementação de políticas públicas se distanciam, cada vez mais, da concepção analítica clássica weberiana e fazem surgir novas perspectivas. 
$\mathrm{Na}$ outra ponta, os profissionais que exercem o elo entre o alto escalão da burocracia e os executores das políticas públicas são chamados de "burocrata de médio escalão" (LOTTA; PIRES; OLIVEIRA, 2014, entre outros). Os "burocratas de médio escalão" são atores responsáveis por coordenarem a implementação da política, na articulação e construção de consensos entre os diferentes atores envolvidos. Sua função estratégica decorre de seu posicionamento, localizado no meio das estruturas organizacionais, são eles que fazem com que as decisões sejam colocadas em ação. Nesse sentido a implementação pode ser pensada não apenas na perspectiva de considerar a atuação dos agentes envolvidos na entrega da política aos beneficiários do serviço, mas também no potencial de inovação, ajuste e aperfeiçoamento que essa etapa representa para a possibilidade de ajustes na formulação da política. Entretanto, apesar de esses agentes desempenharem um papel tão fundamental na implementação, são muitas vezes invisibilizados. Mesmo na pesquisa acadêmica há pouca produção sobre essa categoria.

No caso do PAIC, o papel estratégico dos "burocratas de médio escalão" está na sua capacidade relacional, cuja atuação lhes permite "fazer as costuras" entre os diferentes setores, tecendo e fortalecendo a rede dos arranjos institucionais nas diferentes instâncias. Essa categoria de agentes está representada pelos gerentes regionais e municipais do PAIC e gestores escolares. Eles são encarregados de fazer com que a política seja executada pelos professores ("burocratas de nível de rua") por meio das formações e acompanhamento do trabalho pedagógico nas escolas.

Este artigo sublinha a ideia de que importa ouvir o que os agentes implementadores pensam, pois são esses agentes que na prática dão materialidade à política e definem o nível de sucesso do alcance dos objetivos da política. $O$ que eles pensam faz diferença, pois não são meros executores da política, mas fazedores da política (OLIVEIRA, 2012).

\section{Contexto de surgimento do PAIC}

O Sistema Nacional de Avaliação da Educação Básica $\left(\mathrm{SAEB}^{2}\right)$ foi instituído em 1990. Inspirado nessa avaliação e já tendo participado de outras experiências, o Ceará foi um dos primeiros estados no país a realizar avaliações subnacionais externas em 1992. Nos anos seguintes, a experiência piloto se firmou como Sistema Permanente de Avaliação da Educação Básica do Ceará (SPAECE). Em 2003, o SPAECE já abrangia todos os municípios cearenses.

Os diversos ciclos realizados pelo SPAECE revelaram a existência de sérios problemas na fase de alfabetização, que interferem nas aprendizagens posteriores dos alunos e são retratadas na $4^{a}$ série (atual $5^{\circ}$ ano) pelos baixos indicadores de qualidade e eficiência da educação básica. Os resultados do SAEB de 2003 vieram endossar esse diagnóstico, ao revelarem que mais de 70\% das crianças do estado do Ceará apresentavam competência abaixo do nível desejado.

O SPAECE foi criado com o objetivo de subsidiar a formulação de políticas públicas educacionais voltadas para melhoria da aprendizagem dos alunos, tendo como base o desempenho aferido nas avaliações. Em 2006, com mais de década da implementação do SPAECE, os dados do Censo Escolar apontavam que de cada 100 alunos matriculados no ensino fundamental do $1^{\circ}$ ao $5^{\circ}$ ano nas escolas públicas do Ceará, 26 estavam com atraso escolar de um ao ou mais.

2 O SAEB tem como principal objetivo realizar um diagnóstico da educação básica brasileira e para isso avalia o $2^{\circ}$, $5^{\circ}$ e $9^{\circ}$ anos do ensino fundamental e o $3^{\circ}$ ano do ensino médio. 
Diante do quadro apresentado, em 2004, várias entidades no estado se uniram em busca de soluções para a grave situação educacional e criaram o Comitê Cearense para a Eliminação do Analfabetismo Escolar (CCEAE). Com a união de várias universidades e órgãos públicos foi realizada uma pesquisa ampla com o objetivo de identificar os principais problemas que poderiam ser as causas analfabetismo dos alunos, revelados no desempenho destes nas avaliações. A partir dessa pesquisa foram diagnosticados sérios problemas, dentre eles: infraestrutura deficiente nas escolas, mau uso do tempo das aulas, ausência de metodologia na alfabetização, estrutura curricular inadequada para a formação de professores alfabetizadores, não obrigatoriedade do estágio supervisionado. Do total dos 8.000 alunos avaliados, apenas $15 \%$ podiam ser considerados alfabetizados plenamente.

Os resultados da pesquisa ocasionaram uma grande mobilização social, unindo vários órgãos e entidades em busca do combate ao analfabetismo escolar. Nesse contexto, em 2007, nasceu o Programa de Alfabetização na Idade Certa (PAIC), a partir do qual o estado assumiu o compromisso de apoiar os municípios cearenses na melhoria da qualidade de ensino, com foco na alfabetização inicial. O pacto foi assinado entre o governo do estado e os 184 municípios cearenses, colocando em prática uma experiência de coordenação federativa entre estados e município, cujo desenho é baseado no princípio de colaboração.

O compromisso dos municípios envolvia várias ações entre as quais a valorização e profissionalização dos docentes, revisão de planos de cargos, carreira e remuneração do magistério municipal, definição de critérios técnicos para a seleção de diretores escolares, implantação de sistemas municipais de avaliação de aprendizagem de crianças, ampliação do acesso à educação infantil, e adoção de políticas locais para incentivar a leitura e a escrita. Em contrapartida, o estado do Ceará se comprometia com oferecer aos municípios apoio à gestão municipal, formação continuada para os professores da educação infantil ao $2^{\circ}$ ano do ensino fundamental, livros de literatura infantil para as salas de aula e materiais didáticos para professores e alunos.

Para o êxito da implementação se formou uma rede de relações entre diferentes agentes e instituições com a finalidade de garantir que todos os alunos fossem alfabetizados. O PAIC foi estruturado inicialmente em cinco e eixos: a) Gestão da Educação Municipal; b) Avaliação Externa; c) Alfabetização; d) Educação Infantil; e, e) Literatura Infantil e Formação do Leitor. Posteriormente, o PAIC passou a se constituir por seis eixos, pois o eixo da alfabetização foi transformado e dividido em dois: o eixo do ensino fundamental I e o eixo do ensino fundamental II. Pode-se observar que as temáticas de cada um dos eixos vão se entrelaçando, de forma que cada eixo dá sustentação a outro.

Para o escopo deste trabalho, daremos destaque aos eixos de Gestão da Educação Municipal e Avaliação Externa, o que nos ajudará a compreender como o PAIC possibilitou que as avaliações externas estaduais ganhassem a importância que apresentam atualmente no estado do Ceará, especialmente por utilizar os resultados das avaliações como diagnóstico e o material didático como apoio ao trabalho do professor. Algumas pesquisas mostram como o PAIC provocou mudanças no cotidiano escolar, seja pelas formações recebidas, pelos materiais disponibilizados, ou pela presença efetiva das avaliações externas e seus resultados (FONSECA, 2013; GOMES, 2013). O programa, cujo regime de colaboração demonstra a forte presença da coordenação estadual, teria levado as escolas a cumprir "o horário das aulas, o currículo e o calendário escolar" (SEGATTO, 2015, p. 153).

Para garantir a estrutura institucional necessária ao andamento das políticas de cooperação com os municípios e, especialmente, das ações do PAIC, foi criada a Coordenadoria de Cooperação com os Municípios (COPEM), e seus equivalentes regionais, os Núcleos de 
Cooperação com os Municípios (NRCOM), atuais Células de Cooperação com os Municípios (CECOM). No nível estadual, situada na SEDUC, a COPEM conta com uma equipe central e núcleos regionais responsáveis por criar um arranjo que viabiliza o regime de colaboração e a cooperação entre a SEDUC e os municípios. A COPEM, cuja finalidade é definir políticas e estruturar ações em prol da qualidade da educação no estado, coordena as ações do PAIC e mantém uma relação direta com a equipe do PAIC - localizada nas secretarias de educação dos municípios realizando atividades de acompanhamento, avaliação e apoio técnico. No nível regional, a CECOM é um órgão dentro das Credes com a equivalência da COPEM na SEDUC. Assim, em cada uma das 21 Credes do estado, foi implantada uma dessas unidades que é dirigida por uma gerente regional, uma coordenadora e sua equipe. A CECOM é um dos principais instrumentos de intermediação entre o estado e os municípios, atuando diretamente com as escolas e seus agentes. Dessa forma, as equipes da CECOM exercem um papel fundamental no acompanhamento técnico-pedagógico e nos processos de assessoria aos municípios, por meio de visitas periódicas, que são intermediadas e acompanhadas pelas equipes do PAIC que é coordenada pelo gerente municipal. Em cada um dos 184 municípios cearenses, existe uma equipe do PAIC que é responsável por coordenar os seis eixos do programa. Essa equipe é formada por um gerente municipal e a quantidade de membros da equipe vai depender do tamanho da rede de ensino de cada município. Além das formações, a equipe é responsável pelo acompanhamento do desenvolvimento da aprendizagem dos alunos, suporte às avaliações externas, apoio pedagógico aos professores e aos diretores, entre outras funções. A estrutura organizacional do PAIC nas diferentes instâncias encontra-se especificada a seguir.

Imagem 1 - Estrutura Organizacional do PAIC

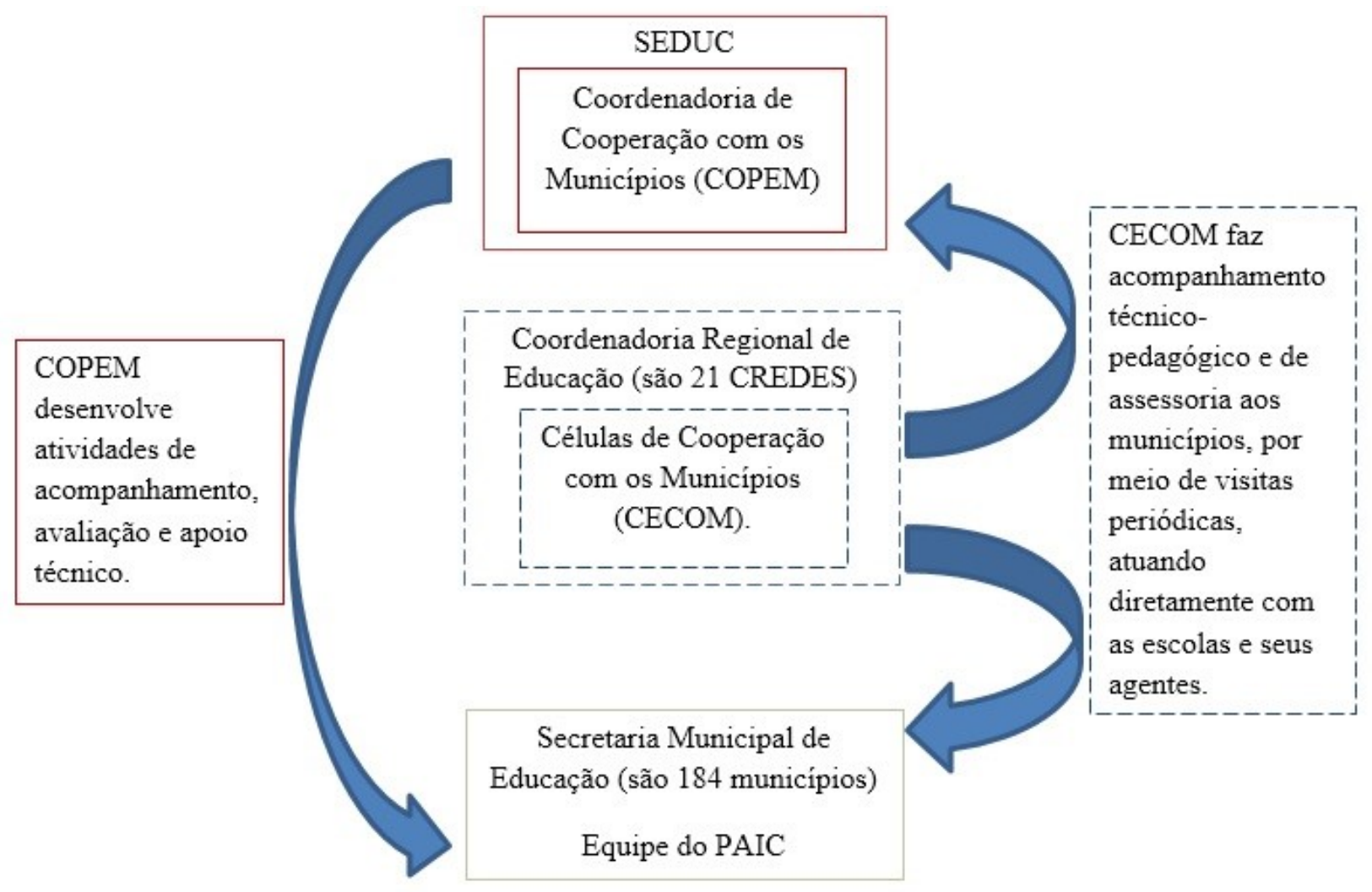

Fonte: Elaboração própria a partir dos dados da SEDUC - Ceará. 
A COPEM e a CECOM são agências que têm a responsabilidade direta de administrar os eixos do PAIC, possibilitando que suas ações sejam executadas com eficiência nos municípios pelos gerentes do PAIC e equipe. Através dessa organização, o PAIC consegue atender aos diferentes eixos já citados, cujo estabelecimento cria uma série de constrangimentos, pois conduzem as práticas dos agentes em um mesmo sentido. As metas de cada eixo foram definidas no Protocolo de Intenções, assinado pelos gestores do Estado e municípios, visando o desenvolvimento pleno do PAIC.

Para o êxito da implementação é necessário que uma série de fatores, agentes, instituições forme uma rede de relações capaz de gerar ações que levem ao sucesso da aprendizagem de todos os alunos na alfabetização. Nesse sentido, se faz necessário a convergência dos objetivos dos diferentes eixos que envolvem a ampliação do atendimento da Educação Infantil, a ênfase na formação do leitor, com fluência e compreensão, o compromisso em oferecer cooperação técnico-pedagógica aos municípios para a implantação e implementação de propostas didáticas de alfabetização, viabilizando a formação docente continuada e em serviço nos municípios. Também está previsto tanto a produção de material didático estruturado e material de apoio pedagógico, quanto a formação de gestores para incrementar a utilização dos resultados das avaliações externas pelos municípios como forma de orientar políticas educacionais locais. A estrutura do PAIC promove o fortalecimento institucional dos sistemas municipais de ensino, cuja assessoria técnica põe ênfase no resultado da aprendizagem.

Além dos eixos que estruturam a operacionalização do PAIC, e constrangem a atuação dos burocratas, existe também o sistema de incentivos. Sendo assim, foram criadas duas políticas de incentivos para os municípios e escolas: o Prêmio Escola Nota Dez e novas regras para o Imposto de Circulação Mercadorias e Serviços (ICMS) para potencializar as ações do PAIC. Em 2008, o governo do estado alterou a distribuição do ICMS com base em critérios que beneficiam os municípios em função da taxa de aprovação obtida a partir dos resultados dos alunos ${ }^{3}$. Esse modelo de incentivo está alinhado ao modelo de gestão pública por resultados, porque visa a induzir as gestões municipais e escolares a se esforçarem mais por melhores resultados, e a participarem ativamente da corrida pelo sucesso da alfabetização de suas crianças.

O Prêmio Escola Nota Dez, criado em 2009, também funciona como política indutora para as escolas melhorarem seus resultados e política apoiadora às escolas com menores resultados. Premia até 150 escolas públicas com melhores resultados no IDE - Alfa (Índice de Desempenho Escolar no $2^{\circ}$ Ano do EF), IDE - 5 (Índice de Desempenho Escolar do $5^{\circ}$ Ano do EF) e IDE - 9 (Índice de Desempenho Escolar do $9^{\circ}$ Ano do EF) do Ensino Fundamental nas avaliações do SPAECE, e oferece apoio financeiro as escolas públicas em igual número das premiadas de $5^{\circ}$ e $9^{\circ}$ anos que obtiverem os menores resultados.

O principal objetivo do Prêmio é promover equidade entre as escolas e oportunizar ações de cooperação técnica pedagógica entre as escolas premiadas e as escolas apoiadas. Os sistemas de incentivos (Prêmio Escola Nota Dez e o ICMS) potencializam as ações do PAIC.

\footnotetext{
${ }^{3}$ Decreto 20.306, Art. $1^{\circ}$ I - 75\% (setenta e cinco por cento) referente ao Valor Adicionado Fiscal VAF; II - 18\% (dezoito por cento) em função do Índice Municipal de Qualidade Educacional de cada município, formado pela taxa de aprovação dos alunos do $1^{\circ}$ ao $5^{\circ}$ ano do ensino fundamental e pela média obtida pelos alunos de $2^{\circ}$ e $5^{\circ}$ ano da rede municipal em avaliações de aprendizagem; III - 5\% (cinco por cento) em função do Índice Municipal de Qualidade da Saúde de cada município, formado por indicadores de mortalidade infantil; IV - 2\% (dois por cento) em função do Índice Municipal de Qualidade do Meio Ambiente de cada município, formado por indicadores de boa gestão ambiental (CEARÁ, 2008).
} 


\section{O alinhamento discursivo na entrega da política}

Para o escopo desse trabalho foi selecionado um eixo do instrumento de entrevista desenvolvido para a pesquisa de campo, que investiga o uso e a apropriação dos resultados das avaliações externas pelos agentes dos diferentes níveis da burocracia educacional. Como se verá adiante, buscamos investigar se a apropriação de gestores e professores a respeito das do uso dos descritores das avaliações do SPAECE se reflete nas suas narrativas e em que medida se poderia estabelecer algum contraste entre as construções narrativas dos "burocratas de nível de rua" e dos "burocratas de médio escalão", a partir das percepções sobre o PAIC.

As escolas selecionadas foram contempladas pelo Prêmio Escola Dez com premiação (escolas com melhores notas) e auxílio financeiro (escolas com notas mais baixas). Trata-se de quatro pares de escolas localizadas na região do Cariri, com a incumbência de desenvolver ações de cooperação pedagógica entre si, a fim de que a escola premiada auxilie a escola apoiada a melhorar seus resultados dentro de um prazo de dois anos. A partir da observação dos encontros de formação que reunia agentes de diferentes níveis da política, pôde-se constatar que a atuação e as interações estabelecidas entre esses agentes são moldadas por diversas pressões, valores e objetivos que perpassam a implementação da política em contextos de coordenação federativa.

As orientações metodológicas aqui delineadas são de natureza qualitativa e interpretativa, interessadas na compreensão do que acontece na vida social, e de inspiração etnográfica, para dar conta da complexidade necessária à apreensão dos processos de construção de sentido (BASTOS; BIAR, 2015, p. 103). A análise do material empírico, gerado a partir das entrevistas e coletado a partir dos documentos, foi realizada com base em uma abordagem teórico-metodológica que considera na análise os aspectos discursivos, especificamente: a Análise de Narrativa.

A Análise de Narrativa consiste em uma técnica interdisciplinar de análise de discurso útil especialmente para dados de entrevista. A ideia fundamental que apoia esse tipo de análise é a de que, quando narramos eventos, damos forma a experiências de vida e de trabalho de forma a construir sentido, sequência e coerência a diferentes eventos. Ao narrativizar a vida, isto é, ao transformar experiências em linguagem, em discurso, necessariamente nos posicionamos em relação a fatos, contextos, pessoas e até em relação a nós mesmos. E são esses posicionamentos que interessam à Análise de Narrativa. Acredita-se que, analisando histórias, podemos alcançar e aprofundar inteligibilidades sobre o que acontece na vida social.

Para ilustrar a análise, seguem alguns excertos que expressam a percepção de agentes de diversos níveis da burocracia educacional. A fala dos agentes está transcrita sem edições, e de modo a preservar nuances da oralidade. Para cada agente da burocracia educacional foi desenvolvido um instrumento de entrevista específico, com quatro blocos temáticos. A quantidade de perguntas podia variar de um bloco para o outro, em função do tema, e havia alguma flexibilidade no desenvolvimento das entrevistas por serem semiestruturadas.

As primeiras narrativas aqui apresentadas correspondem ao discurso da burocracia de médio escalão, pois os excertos foram selecionados a partir de uma entrevista realizada com uma ex-secretária municipal de educação de um dos municípios das escolas selecionadas. A entrevista com duração de 33 minutos foi realizada em outra repartição municipal (Fórum) e gravada com autorização da entrevistada. A ex-secretária municipal de educação atuou como professora de diversos segmentos da educação, desde 1998, quando foi aprovada em concurso público. Em 2012 foi convidada para exercer o cargo, onde ficou até meados de 2017. 


\section{Excerto 1:}

Entrevistadora: Quais são as contribuições do Prêmio Escola Nota Dez para as escolas?

Secretária Municipal: Olha! É [...] Tem a contribuição financeira que é inegável, o dinheiro que vem para melhorar a escola é, sem sombra de dúvida, muito bem-vindo, você poder melhorar a escola, poder ter material disponível, sem sombra de dúvidas, mas o prêmio mesmo é de você ter conseguido alfabetizar as crianças na idade certa, o prêmio... A vaidade como professora que você não pode deixar de ter, tipo - 'eu sou professora nota dez, meus alunos foram 100\% alfabetizados'. Para mim, é essa a maior contribuição, é o reconhecimento, é o aumento da autoestima! Porque você é professor e você sabe o quanto a nossa profissão que é tão desgastada, tão sofrida e de repente vem uma política como o prêmio para valorizar o professor, e aí os outros professores também querem ser, os outros municípios, aí todo mundo vai querer... Não existe uma competição, mas acaba existindo, todo mundo vai querer ser melhor por conta do reconhecimento, todo mundo quer ficar no verde escuro e todo mundo quer ser nota dez.

\section{Excerto 2:}

Entrevistadora: É possível identificar mudanças nas escolas que já participaram do Prêmio Escola Nota Dez?

Secretária Municipal: Éeee. Primeiro é a questão do foco, ééé eles vivem em função, eles trabalham o ano inteiro, desde fevereiro quando começam as aulas, entendeu? E a escola trabalha nessa perspectiva, nesse foco. Todas as ações da escola com a família, está entendendo? É em torno desse resultado, os pais são chamados, o pessoal das séries que vão ser avaliadas, é repassado para eles, entendeu? Há um cuidado com a frequência dos alunos, está entendendo? Um acompanhamento cotidiano. Faltou um dia? O exército da escola cai em cima: 'O que foi? Porque foi?' Eu também percebo que os pais dos meninos, que eles também mudaram, ano passado nós tivemos problemas com o transporte, mas os pais se responsabilizam de trazer a criança mesmo que o transporte escola não vá naquele dia, porque eles também abraçaram a proposta.

\section{Excerto 3:}

Entrevistadora: Qual a sua avaliação do PAIC?

Secretária Municipal: Eu acho a criação do PAIC foi de uma sensibilidade enorme! Por que assim... Até então, o que aa gente via mesmo, era escola pública produzir analfabetos funcionais, os meninos chegavam ao ensino médio sem nem saber ler direito, nem escrever, eram incapazes de ler e escrever um texto. Se você for ver a elaboração de uma questão elaborada para o aluno do segundo ano, a maturação do segundo ano e for ver uma questão do Enem, é na mesma perspectiva, dentro dos graus de dificuldade. Eu acho que foi de uma sensibilidade enorme a criação do PAIC! Deu norte a educação nos municípios, sabe? De uma certa forma forçou o planejamento, a rotina, tá entendendo? Não é de qualquer jeito, se trabalha a alfabetização com o letramento, que foi a parte mais importante, é a criança saber o que ela está lendo, não só decodificar as letras, porque a criança que lê bem, ela escreve bem, então assim, foi de uma sensibilidade e a proposta foi tão assim, tão fantástica que foi ampliada para o fundamental II, entendeu? E até para o país. O PNAIC (Pacto Nacional pela Alfabetização na Idade Certa) ainda não teve o mesmo sucesso do PAIC, primeiro por causa da dimensão, que é 
federal e segundo... O PAIC ele foi abraçado de fato e de verdade, existia todo o interesse do gestor público, para você ver que faz a grande diferença, que tem a ver com a vaidade, na entrega do premio eles são convidados, são altamente envolvidos, o nosso foi um momento único, de muita festa.

\section{- Mulher, é uma verdadeira festa!}

No excerto 1 pode ser identificada uma narrativa breve, não-canônica. De acordo com Bamberg e Georgakopoulou (2008), esses são segmentos menores, que tratam de histórias genéricas, hipotéticas ou projetadas para o futuro. A partir das expressões grifadas no excerto 1 , se pode perceber como a narrativa é individualizada, e fala menos de um programa do que de recompensas (materiais ou simbólicas) pessoais ou do grupo a que a narradora pertence (mais para o final do excerto). Essas conquistas (financeiras, vaidade, reconhecimento, autoestima, valorização, ser melhor) se referem quase todas a um campo semântico do discurso individualista do mérito.

Com alguma hesitação, a secretária municipal diz que, além do ganho financeiro, o Prêmio traz prestígio. Parece haver um constrangimento em admitir que o ganho financeiro seja bem-vindo. Logo em seguida, ela avança dizendo que 'melhor ainda é conseguir alfabetizar as crianças na idade certa', e faz essa afirmação de forma enfática. Parece querer acentuar que mais que o valor financeiro está sua satisfação com o objetivo alcançado. No entanto, prossegue falando da vaidade em ser uma 'professora nota dez', ou seja, além do ganho material, existe um ganho simbólico: o reconhecimento, porque o trabalho ganha visibilidade e se torna motivo de vaidade. A secretária municipal destaca que esse prêmio traz reconhecimento e o aumento da autoestima dos professores. O desenho do Prêmio Escola Nota Dez reside no bojo do PAIC, cujo foco está na formação dos professores entre pares. Que valores estariam por trás dessas narrativas? O professor não tem seu trabalho reconhecido? $\mathrm{O}$ prêmio seria um incentivo com a finalidade de se induzir o desenvolvimento de um bom trabalho pedagógico?

Quando a entrevistada afirma que 'todo mundo vai querer ser melhor por conta do reconhecimento, todo mundo quer ficar no verde escuro' se percebe como o discurso está pautado na competição e na meritocracia. As dimensões material e simbólica do prêmio são sempre acompanhadas de prestígio e justificadas pela meritocracia.

A cor atribuída aos resultados nas tabelas que representam os níveis satisfatórios de desempenho dos alunos é o verde escuro. E na resposta também se percebe um alinhamento com o objetivo da política que visa à plena alfabetização de todas as crianças. Por esse motivo, a expressão 'todo mundo quer ficar no verde escuro' mostra que a interpretação dos resultados foi incorporada pelos professores e gestores. O incentivo do prêmio parece configurar um arranjo promove articulação entre os atores de diferentes níveis.

No excerto 2 pode ser identificada uma construção narrativa em que estão todos mobilizados em torno de um objetivo comum, não apenas os agentes escolares, mas também as famílias. A secretária municipal fala da "questão do foco" do quanto "vivem em função" ou "trabalham o ano inteiro". A generalização indica uma mobilização de todos os atores para se chegar a determinado resultado, inserindo inclusive a família nesse objetivo. Embora seja mais inclusivo em torno de atores sociais, a ênfase permanece em direção a um recrutamento (exército) em prol da avaliação e do resultado. Todas as ações são descritas como ações que giram em torno do resultado desejado, previamente estabelecido pelo programa. Os instrumentos de incentivo se transformam em meios pelos quais os agentes burocráticos são constrangidos e 
mobilizados para agirem de determinada forma no desenvolvimento da política. No caso em questão, o prêmio serviria como incentivo para que os professores se esforcem ao máximo para elevar o resultado dos alunos nas avaliações do SPAECE-Alfa.

O foco em torno de um objetivo comum parece construir consenso, de maneira a convergir esforços em uma mesma direção, como é exemplificado na resposta: "cuidado com a frequência dos alunos, um acompanhamento cotidiano". E ainda quando ela afirma "os pais são chamados", envolve e desenvolve alinhamentos, tanto que por fim a entrevistada afirma: "os pais se responsabilizam de trazer a criança mesmo que o transporte escolar não vá naquele dia, porque eles também abraçaram a proposta".

No excerto 3, quando a secretária municipal afirma que 'se você for ver a elaboração de uma questão elaborada para o aluno do segundo ano, a maturação do segundo ano e for ver uma questão do Enem, é na mesma perspectiva, dentro dos graus de dificuldade', ela parece demonstrar compreensão acerca da formulação em que se baseiam as avaliações em larga escala e confiança na utilização dos indicadores e em seus resultados, como parâmetros. Ao dizer que os itens estão em uma 'mesma perspectiva, dentro dos graus de dificuldade', se supõe que ela compreenda como essa metodologia permite a comparabilidade entre os itens. De fato, os itens do SPAECE, assim como as avaliações nacionais (SAEB/Prova Brasil e o Exame Nacional do Ensino Médio - ENEM), são formulados de acordo com a Teoria da Resposta ao Item (TRI) metodologia que permite a comparabilidade entre anos e séries e entre os resultados das avaliações ao longo do tempo, e que constitui uma vantagem em relação à teoria clássica.

Quanto aos resultados produzidos, a entrevistada sinaliza a percepção de que houve alterações positivas por estabelecer um contraste temporal, onde antes: "a escola pública produzir analfabetos funcionais", e agora: "a criança saber o que ela está lendo, não só decodificar as letras". Sua percepção acerca do PAIC, também parece ser bastante positiva, pois argumenta que "a proposta foi tão assim, tão fantástica que foi ampliada para o fundamental II e até para o país". Ela está se referindo ao fato de que o programa, que a princípio serviria apenas à alfabetização, teve ampliação para outros segmentos. De fato, em 2011 o PAIC ampliou-se e passou a se configurar como PAIC +5 e passou a atender da Educação Infantil ao $5^{\circ}$ ano do Ensino Fundamental. Em 2015, o PAIC teve suas ações ampliadas com o PAIC MAIS e passou a atender do $6^{\circ}$ ao $9^{\circ}$ ano do ensino fundamental II a fim de fortalecer a aprendizagem dos estudantes dessa etapa. O programa tem na Formação de Professores do EFII uma de suas ações mais importantes, além de fomentar a criação de políticas para esse segmento, com orientações de acompanhamento, mecanismos de reconhecimento e incentivo.

Quando a secretária municipal se refere à ampliação do programa para o país, está se referindo ao PNAIC, que foi inspirado na experiência do PAIC, no Ceará. No entanto, ainda sobre os resultados, a entrevistada estabelece uma diferença entre o PAIC e o PNAIC: "O PAIC foi abraçado de fato e de verdade, existia todo o interesse". Nesse excerto, a entrevistada destaca ainda o interesse do gestor público, pois o prêmio gera não apenas ganho material, mas mexe com a vaidade, por conta do já mencionado ganho simbólico. O momento da premiação é descrito como uma vitória que justifica a comemoração e a promoção de muita festa.

Nos dois próximos excertos, vamos analisar as narrativas de um professor e de um coordenador, considerados nessa perspectiva metodológica como "burocratas de nível de rua", pois são os agentes que estão em contato direto com os beneficiários da política (alunos e responsáveis), e são responsáveis pela entrega da política ao seu destino final.

O excerto a seguir foi retirado de uma entrevista com uma professora alfabetizadora de uma escola premiada e teve a duração de 25 minutos. A professora de 38 anos trabalha na escola 
desde 1997, nas séries iniciais do ensino fundamental. É graduada e pós-graduada na área educacional. A entrevista foi realizada na escola, onde a professora se encontrava em seu horário destinado ao planejamento de estudo.

\section{Excerto 4:}

Entrevistadora: Houve alguma alteração na forma da escola avaliar os alunos, a partir da obtenção do Prêmio? Dê exemplos.

Professora: Houve! Em que sentido? Houve sim, porque assim, de primeiro a gente avaliava os alunos só mais nas atividades, não tinha aquela prova escrita direto [...] e hoje nós avaliamos de três formas, nós avaliamos com provas, trabalhos, atividades realizadas em sala de aula a partir do prêmio. Então, eu acho que mudou. As provas são elaboradas pelos professores, mas é assim: tem que ser toda baseada nos descritores, para cada descritor a gente tem que fazer uma questão ou duas sobre aquele descritor, conforme a necessidade da sala.

Entrevistadora: O planejamento, vocês também fazem baseado nos descritores?

Professora: Sim, também, inclusive nós temos a nossa rotina semanal que ela vai ser distribuída, o que vai ser trabalhado a cada dia, nas aulas de português e matemática.

O exerto 5 foi retirado de uma entrevista feita com a coordenadora de uma escola premiada. Teve a duração de 20 minutos e foi gravada com autorização da entrevistada, na própria escola onde trabalha. A coordenadora, também considerada nessa perspectiva metodológica como um "burocrata de nível de rua", é graduada e possui especialização na área da educação. Começou a atuar na escola em 2014, ano em que a escola recebeu o Prêmio Escola Nota Dez na alfabetização.

\section{Excerto 5:}

Entrevistadora: De que forma é feita a divulgação dos resultados do SPAECE-ALFA entre alunos, pais e escola? E antes do Prêmio, como era feito?

Coordenadora: Antes a gente usava apenas para divulgar, agora todo planejamento a gente procura estar mostrando os resultados e criar estratégias para trabalhar as dificuldades, porque a prova trazia o resultado nu e cru, hoje a gente tem os resultados por alunos, por questão, é um norte para desenvolver o trabalho.

No excerto 4, a resposta da professora destaca a modificação na forma de avaliar o aluno, assim como a própria prática pedagógica, a partir da compreensão acerca da utilização dos indicadores provenientes das avaliações em larga escala. Ela ressalta que houve um incremento na utilização dos descritores, por parte dos professores, no próprio planejamento das aulas e na elaboração das atividades pedagógicas propriamente ditas.

No excerto 5 a resposta do coordenador mostra os descritores como centrais na organização temporal da narrativa. Os resultados são utilizados não só com função diagnóstica, mas também como norteadora de todo o trabalho. Ao afirmar que os resultados são utilizados para 'criar estratégias para trabalhar as dificuldades', a coordenadora está dizendo como os 
resultados informam a situação do aluno e podem ser utilizados na própria prática pedagógica, como 'um norte para desenvolver o trabalho'. Ou seja, as avaliações em larga escala além de servirem como parâmetros também estão sendo utilizadas para informar a prática pedagógica, como orientação do que precisa ser feito.

De modo geral, os "burocratas de nível de rua" recorrem a um discurso técnico e privilegiam em suas falas o uso dos indicadores do sistema de avaliação vem informando a prática pedagógica na sala de aula, especialmente ao citar a utilização dos descritores. De maneira geral, avaliam positivamente o programa e de maneira acrítica, naturalizando e tratando como consenso os modos de avaliação e os métodos empregados. Valorizam as modificações na prática pedagógica como resultado das formações em serviço, entre pares, ressaltam a rotina semanal de planejamento, e destacam que as formações trazem novas formas de trabalhar a intervenção junto ao aluno.

Por sua vez, entre as narrativas dos "burocratas de médio escalão" se percebe uma maior ênfase nos instrumentos de indução da política, e do quanto os incentivos podem operar como um potente instrumento motivacional. Há um entendimento de que o prêmio justifica o esforço e a busca de se atingir as metas - novamente a busca pelo resultado e a compreensão pautada no mérito.

\section{Considerações finais}

O PAIC entrou na agenda política do Ceará para que todas as crianças estivessem alfabetizadas até os oito anos de idade, e para isso a formação continuada é entendida como um componente essencial da profissionalização docente. $O$ foco na formação docente, mais especialmente na formação em serviço, enfatiza a troca de conhecimentos e o efeito multiplicador da formação nos diferentes níveis. Ao investigar como acontece o alinhamento discursivo da implementação do PAIC entre os diferentes atores envolvidos, nos diferentes entes federativos, buscamos compreender como esses atores produzem sentido e dão significado às suas ações em relação ao programa.

Além dos eixos que estruturam a operacionalização do PAIC, e constrangem a atuação dos burocratas, existe também o sistema de incentivos. As políticas de incentivos criadas no âmbito do PAIC - como o Prêmio Escola Nota Dez e a cota parte do ICMS - podem ser consideradas as grandes responsáveis por estimularem os gestores municipais e educacionais a investirem nos objetivos dessas políticas, já que tanto os municípios quanto as escolas são beneficiados.

Para analisar o uso e a apropriação dos resultados das avaliações externas pelos gestores e professores, buscamos estabelecer algumas diferenças entre as construções narrativas dos "burocratas de nível de rua" e dos "burocratas de médio escalão". Diante das perguntas sobre o Prêmio Escola Nota Dez analisamos em que bases e discursos suas narrativas se apoiam. A partir das entrevistas de pesquisa, buscamos entender como esses diferentes agentes compreendem a política formulada. Buscamos perceber também se, nesse processo de colocar "o plano em ação", produzem sua (re)construção coletivamente, considerando a dimensão interpretativa de produção de sentido dos atores envolvidos (CAPELLA, 2016; LIMA; D'ASCENZI, 2013).

Em resumo, os resultados da pesquisa indicam que os "burocratas de médio escalão" parecem apresentar alta adesão com o discurso do mérito e do "sucesso" que permeia o programa e demonstram maior autonomia em suas atribuições que os "burocratas de nível de rua". Em função da complexidade de atribuições e competências nas formas de coordenação, que 
envolve repasse de recursos e mecanismos de indução para adesão a essas políticas, os "burocratas de médio escalão" demonstram maior autoria, criatividade e inovação em sua atuação. Como são responsáveis por coordenarem a implementação da política, promovendo articulação e construção de consensos entre os diferentes atores envolvidos, seu lugar de atuação lhes permite algum grau de discricionariedade. Como sua função se localiza no meio das estruturas organizacionais, o foco de sua atuação está em "fazer as costuras" entre os diferentes setores, tecendo e fortalecendo a rede dos arranjos institucionais nas diferentes esferas da política. O desempenho da sua função depende da sua capacidade relacional, de interagir dom os mais diferentes atores nos diferentes níveis da burocracia educacional.

Em decorrência de seu posicionamento estratégico, eles são encarregados de fazer com que a política seja executada pelos professores ("burocratas de nível de rua") por meio das formações e acompanhamento do trabalho pedagógico nas escolas. Essa categoria de agentes está representada pelos gerentes regionais e municipais do PAIC e gestores escolares, e são eles que fazem com que as decisões sejam colocadas em ação. As práticas dos agentes da "burocracia de nível de rua" são conduzidas pelos eixos que estruturam a operacionalização do PAIC, e constrangem a atuação dos burocratas. Por suas narrativas, os "burocratas de nível de rua" parecem totalmente alinhados com os objetivos, mecanismos e processos da política, embora chame à atenção a forma como esse alinhamento se dá. Prevalece o aspecto da implementação como um processo hierárquico seguindo a lógica em que os burocratas de nível de rua executam as políticas públicas, formuladas por agentes superiores da estrutura hierárquica e são transformadas em práticas operacionais a serem implantadas. Nessa perspectiva, a atuação dos burocratas nível de rua é controlada por meio de planos, metas e objetivos claramente definidos. Dessa forma, pelas suas narrativas, os professores enquanto "burocratas de nível de rua" se posicionam frente ao PAIC, como quem executa o programa, e não como co-participantes dele. Nesse nível da burocracia, parece que a implementação se dá numa perspectiva top-down dos modelos analíticos de implementação. Além disso, as narrativas com os agentes desse nível apresentam o programa como um ponto de virada na história, e as ações dos agentes estão organizadas sempre em torno do programa e das suas técnicas de avaliação.

As entrevistas realizadas tanto com os "burocratas de médio escalão" quanto com os "burocratas de nível de rua" mostram que as formações promovidas pelo PAIC fizeram com que esses profissionais conhecessem e se apropriassem da matriz de referência das avaliações, do uso dos descritores e habilidades exigidas em cada eixo, assim como passassem a utilizar os resultados das avaliações para realizar intervenções pontuais a favor da aprendizagem dos alunos. No entanto, os diferentes níveis hierárquicos da burocracia educacional se refletem nas narrativas que permitem estabelecer um contraste entre as formas de interação dos agentes e suas respectivas percepções e margem de atuação.

\section{Referências}

BAMBERG, M.; GEORGAKOPOULOU, A. Small stories as a new perspective in narrative and identity analysis. Text $\&$ Talk, v. 28, n. 3, p. 377-396, 2008. DOI: https://doi.org/10.1515/text.2008.018

BASTOS, L.; BIAR, L. Análise de narrativa e práticas de entendimento da vida social. Delta: documentação e estudos em linguística teórica e aplicada, São Paulo, v. 31, n. 4, p. 97-126, 2015. DOI: https://doi.org/10.1590/0102-445083363903760077 
CAPELLA, A. C. Um estudo sobre o conceito de empreendedor de políticas públicas: ideias, interesses e mudanças. Cadernos EBAPE. BR, Rio de Janeiro, v. 14, edição especial, p. 486-505, 2016. DOI: https://doi.org/10.1590/1679-395117178

CAVALCANTE, P.; LOTTA, G. (Orgs.). Burocracia de médio escalão: perfil, trajetória e atuação. Brasília: Enap, 2015.

FONSECA. A. S. A. Programa de alfabetização na idade certa (PAIC): reflexos no planejamento e na prática escolar. 2013. 148 f. Tese (Doutorado em Educação) - Universidade Federal do Ceará, Fortaleza, 2013.

GOMES, A. W. A. Alfabetização na idade certa: garantir a aprendizagem no início do ensino fundamental. Consultoria legislativa. Brasília: Câmara dos Deputados, 2013.

LIMA, L. L.; D'ASCENZI, L. Implementação de políticas públicas: perspectivas analíticas. Revista de sociologia e política, Curitiba, v. 21, n. 48, p. 101-110, 2013. DOI: https://doi.org/10.1590/s0104-44782013000400006

LIPSKY, M. Street-level bureaucracy: dilemmas of the individual in public service. New York: Russell Sage Foundation, 2010.

LOTTA, G. Burocracia e implementação de políticas de saúde: os agentes comunitários na Estratégia Saúde da Família. Rio de Janeiro: Editora FIOCRUZ, 2015. DOI: https://doi.org/10.7476/9788575415481

LOTTA, G.; PIRES, R.; OLIVEIRA, V. Burocratas de médio escalão: novos olhares sobre velhos atores da produção de políticas públicas. Revista do Serviço Público, Brasília, v. 65, n. 4, p. 463-492, out./dez. 2014.

MULLER, P.; SUREL, Y. A análise das políticas públicas. Tradução de Agemir Bavaresco e Alceu R. Ferraro. Pelotas: Educat, 2002. (Coleção Desenvolvimento Social 3).

OLIVEIRA, A. Burocratas da linha de frente: executores e fazedores das políticas públicas. Revista de Administração Pública, v. 46, n. 6, p. 1551-1573, nov./dez. 2012. DOI: https://doi.org/10.1590/s0034-76122012000600007

PIRES, R. Sociologia do guichê e implementação de políticas públicas. BIB, São Paulo, n. 81, p. 5-24, 2017.

SEGATTO, C. O papel dos governos estaduais nas políticas municipais de educação: uma análise dos modelos de cooperação intergovernamental. 2015. 196 f. Tese (Doutorado em Administração Pública e Governo) - Escola de Administração de Empresas, Fundação Getúlio Vargas, São Paulo, 2015.

Recebido em 16/11/2018

Versão corrigida recebida em 28/03/2019

Aceito em 30/03/2019

Publicado online em 02/04/2019 


\section{Maria Océlia Mota}

Doutora em Educação pela Pontifícia Universidade Católica do Rio de Janeiro (PUC-Rio). Mestre em Educação, Comunicação e Periferias Urbanas pela FEBF/UERJ. Pedagoga com especialização em Educação Infantil pelo Centro Universitário Hermínio Ometto-UNIARARAS. Pesquisa políticas púbicas para educação e avaliação na alfabetização. Integra o Laboratório de Avaliação da Educação (LAEd), vinculado ao PPGE da PUC-Rio.

\section{Liana de Andrade Biar}

Doutora em Letras pela Pontifícia Universidade Católica do Rio de Janeiro (PUC-Rio). Professora do Departamento de Letras da PUC-Rio, atuando na graduação em Letras e no Programa de Pós-Graduação em Estudo da Linguagem. Coordenadora adjunta do Grupo de Pesquisa NAVIS (Narrativa e interação social). Seus temas de interesse são: narrativa, estigma e desvio. Integra a Cátedra Sérgio Vieira de Mello da PUC-Rio em convênio com a Agência da ONU para Refugiados.

\section{Maria Elizabete Neves Ramos}

Psicóloga formada pela Universidade Federal do Rio de Janeiro. Cursa o Doutorado em Educação pela Pontifícia Universidade Católica do Rio de Janeiro (PUC-Rio), instituição onde também concluiu o Mestrado em Educação. Pesquisa a implementação do PNAIC no Rio de Janeiro sob a perspectiva dos arranjos institucionais. É integrante do Laboratório de Avaliação da Educação (LAEd), vinculado ao PPGE da PUC-Rio. 